\title{
Uric acid is a risk factor for ischemic stroke and all-cause mortality in the general population: a gender specific analysis from The Tromsø Study
}

\author{
Hilde M Storhaug ${ }^{1,2}$, Jon V Norvik ${ }^{3}$, Ingrid Toft ${ }^{2,3^{*}}$, Bjorn O Eriksen ${ }^{2,3}$, Maja-Lisa Løchen ${ }^{4}$, Svetlana Zykova ${ }^{2}$,
} Marit Solbu ${ }^{3}$, Sarah White ${ }^{5}$, Steve Chadban ${ }^{6}$ and Trond Jenssen ${ }^{2,7}$

\begin{abstract}
Background: The role of serum uric acid as an independent predictor of cardiovascular disease and death is uncertain in the general population. Adjustments for additional cardiovascular risk factors have not been consistent. We examined the association of serum uric acid with all-cause mortality, ischemic stroke and myocardial infarction in a prospective population based study, with several traditional and non-traditional risk factors for cardiovascular disease included in the model.
\end{abstract}

Methods: A population-based prospective cohort study was performed among 2696 men and 3004 women. Endpoints were all-cause mortality after 15 years, and fatal or non-fatal myocardial infarction (MI) and ischemic stroke after 12 years.

Results: 1433 deaths, 659 Mls and 430 ischemic strokes occurred during follow-up. Fully adjusted Cox regression analyses showed that per $1 \mathrm{SD}(87 \mathrm{\mu mol} / \mathrm{L})$ increase in serum uric acid level, the risk of all-cause mortality increased in both genders (hazard ratios, HR men; $1.11,95 \% \mathrm{Cl} 1.02-1.20$, women; 1.16, 1.05-1.29). HRs and 95\% Cl for stroke were $1.31,1.14-1.50$ in men, $1.13,0.94-1.36$ in women, and $1.22(1.09,1.35)$ in the overall population. No independent associations were observed with $\mathrm{Ml}$.

Conclusion: Serum uric acid was associated with all-cause mortality in men and women, even after adjustment for blood pressure, estimated GFR, urinary albumin/creatinine ratio, drug intake and traditional cardiovascular risk factors. After the same adjustments, serum uric acid was associated with 31\% increased risk of stroke in men.

Keywords: All-cause mortality, Gender, Myocardial infarction, Stroke, Uric acid

\section{Background}

Uric acid is the breakdown product of purines from DNA, RNA, ATP and cAMP. In this process hypoxanthine is converted by the enzyme xanthine oxidase to xanthine and further to uric acid. Both steps induce the release of free radicals. Uric acid may accumulate in the body due to increased production (cell death, intake of alcohol or purine rich diet) or decreased elimination (impaired renal function, use of diuretics). Epidemiologic studies show that mean uric acid levels in men increased gradually from the 1920s

\footnotetext{
*Correspondence: Ingrid.Toft@unn.no

2Department of Clinical Medicine, UiT The Arctic University of Norway,

Tromsø, Norway

${ }^{3}$ Section of Nephrology, University Hospital of North Norway, N-9038,

Tromsø, Norway

Full list of author information is available at the end of the article
}

to the 1970s, from less than $210 \mu \mathrm{mol} / \mathrm{L}$ to $360-390 \mu \mathrm{mol}$ [1]. Pre-menopausal women tend to have lower levels than men, probably because of the uricosuric effect of estrogens [2]. The relationship between serum uric acid and cardiovascular disease is not clear. Some epidemiologic studies have reported a relationship between serum uric acid and several cardiovascular conditions [3-10], whereas others have not observed such links [11-15]. The National Health and Nutrition Examination Survey (NHANES I study) [3] reported a significant risk for cardiovascular death with increasing serum uric acid levels. The Framingham Heart study, on the other hand, was not able to confirm these findings when use of diuretics was adjusted for [11]. Two large cohort studies from Japan and Korea, each with 9-10 years follow up could not confirm that serum uric acid was 
a risk factor for either cardiovascular disease or death $[12,13]$. It has been argued that previous studies may not have sufficiently accounted for differences in gender or for risk factors being strongly related to serum uric acid levels, e.g., use of diuretics or renal factors, such as glomerular filtration rate (GFR) and renal dysfunction measured as urinary albumin excretion.

The purpose of the present study was to address uric acid as putative cardiovascular risk factor in a Caucasian population followed for more than 12 years. In order to do so, we chose a stepwise approach with models including various covariates that have and have not been included in previous studies.

\section{Methods}

\section{Study population}

The Tromsø Study is a series of population-based, prospective surveys of inhabitants of the municipality of Tromsø, Norway [16]. In 1994/95, 27.158 subjects were screened (77\% of eligible subjects). All participants at the age of $55-75$ years and $5-10 \%$ of the other age groups $\geq 25$ years were invited to a second visit including a more comprehensive examination 4-6 weeks later. Of the 9057 individuals who were invited 6862 participated (attendance rate $75 \%$ ). Persons with known previous MI $(\mathrm{n}=402)$, ischemic stroke $(\mathrm{n}=190)$ or diabetes $(\mathrm{n}=308)$, defined as self-reported diabetes, use of antidiabetic medication, HbA1c $>6.5 \%$ or non-fasting plasma glucose $\geq 10.0$ $\mathrm{mmol} / \mathrm{L}$, were excluded. Data on uric acid was available in 5700 subjects (Figure 1). The Tromsø Study was conducted by the University of Troms $\varnothing$ in cooperation with The National Health Screening Service. The Regional Committee for Medical Research Ethics approved the study, and all participants gave their written consent.

\section{Measurements}

All measurements and information on risk factors were obtained from baseline data of the $4^{\text {th }}$ Tromsø Study in 1994 /95. Information about presence of diabetes, smoking habits and physical activity was obtained from a selfadministered questionnaire. Blood pressure was recorded in triplet (Dinamap) after 5-min seating, the mean of the second and third measurement was used. Hypertension was defined as systolic blood pressure $(\mathrm{SBP}) \geq 140 \mathrm{mmHg}$ and/or diastolic pressure (DBP) $\geq 90 \mathrm{mmHg}$ and/or current use of antihypertensive medication. Physical activity was classified as active (> 1 hour physical activity/week) or inactive (all others). Smoking habits were classified as nonsmokers or current smokers. Serum HDL-cholesterol was measured after precipitation of lower-density lipoprotein with heparin and manganese chloride. Serum uric acid was measured by photometry with COBAS ${ }^{\circ}$ instruments (Roche diagnostics, Switzerland) using an enzymatic colorimetric test, the uricase/ PAP method. Reference values were $140-340 \mu \mathrm{mol} / \mathrm{L}(2.4-5.7 \mathrm{mg} / 100 \mathrm{~mL})$ for females and $200-415 \mu \mathrm{mol} / \mathrm{L}(3.4-7.0 \mathrm{mg} / 100 \mathrm{~mL})$ for males. Creatinine was analyzed by a modified Jaffe reaction, but since creatinine-based estimation of GFR is better validated for enzymatic creatinine measurements, 111 plasma samples from the 1994/95 survey were thawed and reanalysed with an enzymatic method (Modular P/Roche). Values were fitted to a linear regression model, and recalibrated creatinine values were calculated for all participants. Estimated GFR was calculated according to the CKD-EPI formula [17]: eGFR $=141 \times \min \left(\mathrm{S}_{\mathrm{Cr}} / \mathrm{k}, 1\right)^{\mathrm{a}} \times$ $\max \left(\mathrm{S}_{\mathrm{Cr}} / \mathrm{k}, 1\right)^{-1.209} \times 0.993^{\text {age }} \times([1.018$ if female $]$ and $\times$ [1.159 if black]) where $\mathrm{S}_{\mathrm{Cr}}$ is serum creatinine $(\mathrm{mg} / \mathrm{dL})$, $\mathrm{k}$ is 0.7 for females and -0.411 for males, min indicates the minimum of $\mathrm{S}_{\mathrm{Cr}} / \mathrm{k}$ and max indicates the maxiumum of $\mathrm{S}_{\mathrm{Cr}} / \mathrm{k}$ ). Albuminuria was reported as albumin/creatinine ratio (ACR, $\mathrm{mg} / \mathrm{mmol}$, urinary albumin and creatinine analyses; kits from ABX Diagnostics, Montpellier, France). For each subject, ACR was measured in fresh samples of each of 3 separate urine specimens and the mean of all 3 was used in the analyses.

\section{Outcomes}

The endpoints were death from any cause, first ever nonfatal or fatal myocardial infarction or ischemic stroke. Adjudication of hospitalized and out-of-hospital events was performed by an independent endpoint committee, who thoroughly reviewed data from hospital and out-of-hospital journals, autopsy records and death certificates. Event ascertainment followed a detailed protocol according to established diagnostic criteria. Each case was reviewed separately. Stroke was defined according to the WHO definition, only ischemic strokes were included [18]. Individuals who had died, moved, or emigrated from Troms $ø$ were identified through the population Registry of Statistics Norway. The national 11-digit identification number allowed a linkage to the population Registry of Statistics Norway and ensured a complete follow-up status for all-cause mortality until November $30^{\text {th }}, 2010$ (followup time 15 years). The cardiovascular (CV) endpoint registry was completed until December 31, 2007 (follow-up time 12 years). Data were censored for date of registered emigration, or deaths from causes other than myocardial infarction and stroke.

\section{Statistics}

Data are given as mean \pm SD or median and interquartile range. Uric acid was categorized into gender-specific tertiles. Crude and age-adjusted incidence rates were calculated as events per 1000 person years at risk. Ageadjustment of incidence rates was performed on 10 year age groups with the population of Tromsø in 1995 as the standard population. Multiple linear regression analyses were performed with uric acid as the dependent variable. 
The Tromsø Study 1994/-95, Phase 1:

All inhabitants of the municipality of

Troms $\emptyset>25$ years were invited

27.158 subjects attended

(77\% of the invited)

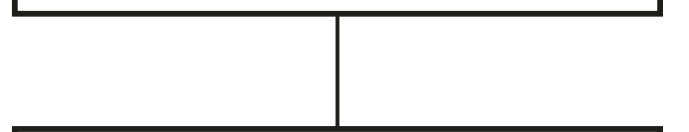

The Troms $\varnothing$ Study 1994/-95, Phase 2:

All participants aged 55-75 years and 5-10\% of all other age groups $\geq 25$ years invited

9057 invited, 6862 consented and attended ( $75 \%$ of the invited)

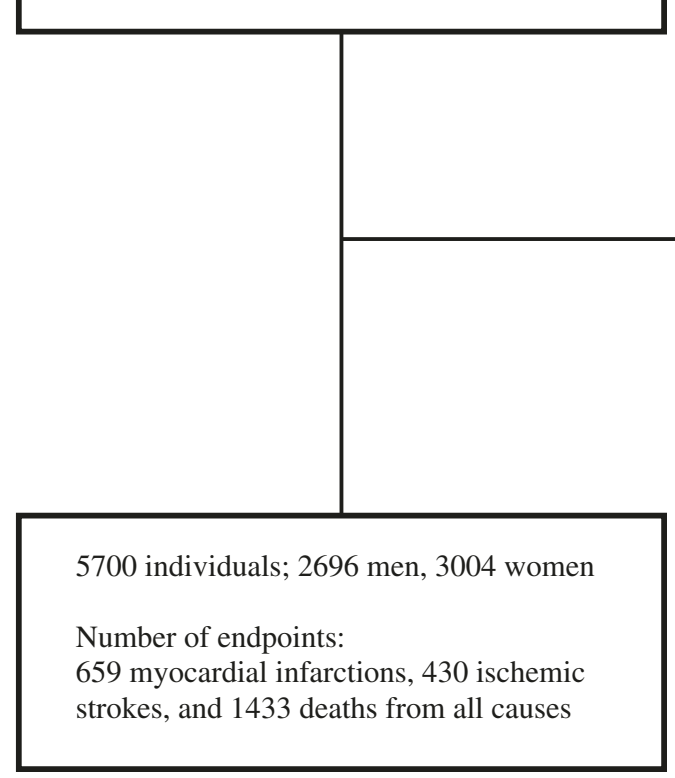

506 individuals excluded due to previous myocardial infarction (402) or stroke (190) or both (86)

308 individuals excluded due to the presence of diabetes*

348 individuals had missing values for serum uric acid

Figure 1 Selection of the study population. * Self-reported diabetes mellitus and/or use of antidiabetic medication and/or HbA1c > 6.5\% and/or non-fasting glucose $\geq 10.0 \mathrm{mmol} / \mathrm{L}$.

Covariates were systolic blood pressure, body mass index (BMI), high density lipoprotein cholesterol (HDL), total cholesterol, smoking status and physical activity. Renal covariates (estimated GFR and ACR) and use of diuretics or antihypertensive drugs were also added to the models in the multivariable analyses. ACR was logarithmically transformed. Cox proportional hazard models were used to investigate associations of uric acid with cardiovascular outcomes and mortality, calculated per $1 \mathrm{SD}(87 \mu \mathrm{mol} / \mathrm{L})$ change in uric acid, in unadjusted, age-adjusted and multivariable analyses. The proportional hazard assumption was checked by visual inspection of the -log-log survival curves. Tests for interactions and non-linearity (by quadratic terms) were assessed in separate models. Non-linear effects were also explored in fractional polynomial regression models. $\mathrm{P}$ values $<0.05$ were considered statistically significant. Most analyses were run using SPSS software version 15.0 (SPSS, INC, Chicago, Illinois), fractional polynomial regression models were performed with STATA/ MP 12.1 (Stata Corp LP, College Station, Texas).

\section{Results}

\section{Baseline characteristics}

Mean serum uric acid was $357 \pm 84 \mu \mathrm{mol} / \mathrm{L}$ for men and $276 \pm 70 \mu \mathrm{mol} / \mathrm{L}$ for women. Figure 2 shows serum uric acid concentrations according to gender and age. In both genders, increasing uric acid was associated with a poorer risk profile in terms of elevated BMI, blood pressure, 


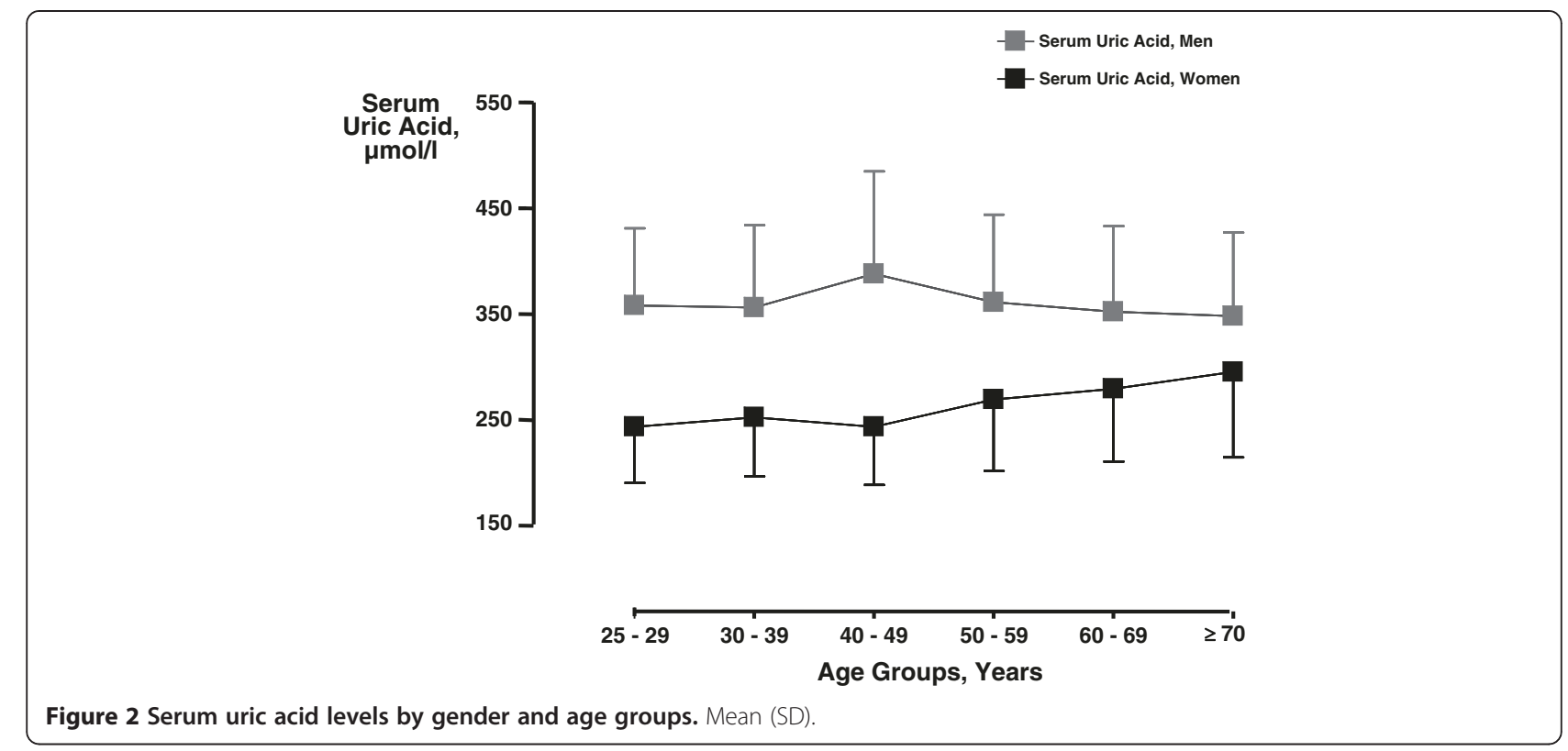

ACR, and proportion of hypertensive persons. Physical activity, renal function and HDL were lower with increasing uric acid concentrations. Only a few subjects were using diuretics and anti-hypertensive medication at baseline in 1994/95 (Table 1).

\section{The association of serum uric acid with renal function and CV risk factors}

The correlation between uric acid and age differed in men and women (men; $\mathrm{r}=-0.09, \mathrm{p}<0.001$, women; $\mathrm{r}=0.17$, $\mathrm{p}<$ 0.001 , Pearson's correlation coefficients), and tested significant for gender interaction $(\mathrm{P}<0.001)$. Results of the multiple linear regression analyses are given in Table 2 . In both genders, standardized beta-coefficients were highest for BMI, HDL-cholesterol, total cholesterol, and GFR. The addition of renal factors (eGFR and ACR; model 5) into the model including drug intake and traditional cardiovascular risk factors, contributed significantly to variation of serum uric acid; adjusted $\mathrm{R}^{2}$ increased from 0.19 to 0.23 in men, from 0.20 to 0.27 in women, and from 0.20 to 0.40 in pooled analyses for men and women together. ACR was independently associated with serum uric acid in women, but not in men, and there was a significant interaction with gender $(P=0.005)$.

\section{Event rates}

Number of events during follow-up were 659 first ever cases of fatal or non-fatal MI, 430 fatal or non-fatal ischemic strokes, and 1433 deaths from all causes. Median observation time was 12.5 years for myocardial infarction and ischemic stroke, and 15.7 years for all-cause mortality. Crude and age-adjusted incidence, for MI and ischemic stroke, picturing absolute risk rates according to increasing tertiles of serum uric acid, are shown in Figure 3. Ageadjusted incidence rate for myocardial infarction was significantly higher in the upper serum uric acid tertile among men, but not in women. Increasing crude and ageadjusted incidence rates with higher levels of uric acid were observed in both genders for ischemic stroke.

\section{Associations between serum uric acid and outcome variables (Cox proportional hazard models)}

In both genders, P-values for linear, increasing trend were $<0.001$ for all endpoints in multivariable, Cox proportional hazard models where the lowest serum uric acid tertile was reference (data not shown). In multivariable analyses calculated per $1 \mathrm{SD}(87 \mu \mathrm{mol} / \mathrm{L})$ increase in uric acid (Table 3), uric acid was independently associated with all-cause mortality in men ( $\mathrm{HR}, 95 \% \mathrm{CI}$; 1.11, 95\% CI 1.02-1.20), women (HR, 95\% CI; 1.16, 1.05 1.29 ), and in the total population (men and women; HR, 95\% CI: 1.13, 1.06-1.21). In fully adjusted, multivariable models, serum uric acid was not independently associated with $\mathrm{MI}$ in any gender or in the mixed population. In both genders, uric acid lost significance when lipids were introduced as covariates. Serum uric acid was strongly associated with ischemic stroke in men after multivariable adjustments (HR, 95\% CI: 1.31, 1.14-1.50). In contrast, significance was lost among women after adjustments for blood pressure and BMI. Test for gender interaction was not significant $(P=0.19)$. In multivariable analysis of the mixed population, adjusted for sex, $87 \mu \mathrm{mol} / \mathrm{L}$ increase in uric acid was associated with a $24 \%$ increase in risk of future ischemic stroke (Table 3). Tests for non-linearity in fractional polynomial models for associations of serum uric acid with the three endpoints were not significant in 
Table 1 Baseline characteristics according to gender and serum uric acid tertiles

\section{Men}

SUA tertiles

N

Age, years

Serum uric acid (SUA), $\mu \mathrm{mol} / \mathrm{L}$

BMI, $\mathrm{kg} / \mathrm{m}^{2}$

$\mathrm{SBP}, \mathrm{mm} \mathrm{Hg}$

$\mathrm{DBP}, \mathrm{mm} \mathrm{Hg}$

Hypertension, $\mathrm{n}(\%)$

Total cholesterol, $\mathrm{mmol} / \mathrm{l}$

$\mathrm{HDL}$ cholesterol, $\mathrm{mmol} / \mathrm{l}$

GFR ckd-epi, $\mathrm{ml} / \mathrm{min} / 1.73 \mathrm{~m}^{2}$

ACR $\mathrm{mg} / \mathrm{mmol}$

Use of antihypertensive drugs, $n(\%)$

Use of diuretics, $\mathrm{n}(\%)$

Current smoker, n (\%)

Physically active, $\mathrm{n}(\%)$

\section{Women}

SUA tertiles

$\mathrm{N}$

Age, years

Serum uric acid (SUA), $\mu \mathrm{mol} / \mathrm{L}$

BMI, $\mathrm{kg} / \mathrm{m}^{2}$

$\mathrm{SBP}, \mathrm{mm} \mathrm{Hg}$

DBP, $\mathrm{mm} \mathrm{Hg}$

Hypertension, n (\%)

Total cholesterol, mmol//

HDL cholesterol, mmol//

GFR ckd-epi, $\mathrm{ml} / \mathrm{min} / 1.73 \mathrm{~m}^{2}$

ACR, $\mathrm{mg} / \mathrm{mmol}$

Use of diuretics, $n$ (\%)

Use of antihypertensive drugs, $\mathrm{n}$ (\%)

Current smoker, n (\%)

Physically active, n (\%)

$\begin{array}{cc}\mid \leq 317 \mu \mathrm{mol} / \mathrm{L} & \| 318-380 \mu \mathrm{mol} / \mathrm{L} \\ 896 & 902 \\ 60 \pm 10 & 59 \pm 10 \\ 276 \pm 33 & 348 \pm 18 \\ 24.7 \pm 2.9 & 25.8 \pm 3.0 \\ 144 \pm 20 & 144 \pm 20 \\ 84 \pm 12 & 85 \pm 12 \\ 482(54 \%) & 546(61 \%) \\ 6.35 \pm 1.19 & 6.40 \pm 1.20 \\ 1.51 \pm 0.40 & 1.40 \pm 0.39 \\ 96.7(90.9,102.4) & 95.5(88.0,102.5) \\ 0.55(0.38,0.96) & 0.51(0.33,1.01) \\ 74(8 \%) & 87(10 \%) \\ 2(0.2 \%) & 5(0.6 \%) \\ 351(39 \%) & 300(33 \%) \\ 301(33 \%) & 268(30 \%)\end{array}$

$\mathrm{I} \leq 244 \mu \mathrm{mol} / \mathrm{L}$

1002

$58 \pm 11$

$206 \pm 28$

$24.0 \pm 3.5$

$138 \pm 23$

$78 \pm 13$

446 (45\%)

$6.63 \pm 1.39$

$1.76 \pm 0.43$

$96.9(90.5,103.0)$

$0.62(0.41,0.96)$

$3(0.3 \%)$

$65(6.5 \%)$

339 (34\%)

$162(16 \%)$
|| 245-297 $\mu \mathrm{mol} / \mathrm{L}$

1001

$60 \pm 10$

$269 \pm 15$

$25.6 \pm 3.8$

$143 \pm 23$

$81 \pm 12$

534 (53\%)

$6.82 \pm 1.29$

$1.69 \pm 0.43$

$93.6(86.0,99.4)$

$0.58(0.41,0.93)$

$7(0.7 \%)$

$107(11 \%)$

315 (32\%)

$177(18 \%)$
III 381-976 $\mu \mathrm{mol} / \mathrm{L}$ 898

$$
59 \pm 11
$$$$
449 \pm 70
$$

$27.3 \pm 3.4$

$146 \pm 20$

$86 \pm 12$

$571(64 \%)$

$6.73 \pm 1.20$

$1.26 \pm 0.38$

$93.4(84.0,101.5)$

$0.54(0.34,1.13)$

$155(17 \%)$

$13(1.4 \%)$

294 (33\%)

$244(27 \%)$

|| 298-681 $\mu \mathrm{mol} / \mathrm{L}$

1001

$62 \pm 9$

$354 \pm 54$

$27.7 \pm 4,6$

$151 \pm 25$

$85 \pm 14$

679 (68\%)

$7.14 \pm 1.32$

$1.54 \pm 0.42$

$89.7(79.4,97.1)$

$0.64(0.42,1.14)$

39 (3.9\%)

148 (15\%)

$278(28 \%)$

$118(12 \%)$
$\mathrm{P}$ value for linear trend

$<0.001$

$<0.001$

$<0.001$

$<0.001$

$<0.001$

$<0.001$

$<0.001$

$<0.001$

0.021

$<0.001$

$<0.001$

$<0.001$

$<0.001$

$P$ value for linear trend

$<0.001$

$<0.001$

$<0.001$

$<0.001$

$<0.001$

$<0.001$

$<0.001$

$<0.001$

$<0.001$

$<0.001$

$<0.001$

0.001

$<0.002$

The Tromsø Study 1994/95.

BMI: Body mass index. SBP: Systolic blood pressure. DBP: Diastolic blood pressure Hypertension: SBP $\geq 140 \mathrm{mmHg}$ and/or DBP $\geq 90 \mathrm{mmHg}$ and/or self-reported use of antihypertensive medication. Physical active: Self-reported hard physical activity $\geq 1 \mathrm{hr}$ per week (yes / no).

GFR: Glomerular Filtration Rate according to the CKD EPI formula [17]. ACR: Urinary albumin/creatinine ratio (mean of 3 urine samples).

any gender. Cox regression analyses were also performed without exclusion of persons with diabetes and previous cardiovascular disease. Risk estimates for uric acid and myocardial infarction in fully adjusted analyses did not change substantially (HR and 95\% CI for men were 1.06, 0.99-1.14, $\mathrm{p}=0.06$ and for women 1.04, 0.92-1.14, $\mathrm{p}=0.5$ ). We also stratified the study population according to serum uric acid levels higher or lower than the hospital laboratory's upper reference range. Belonging to the group with higher uric acid levels was not significantly associated with myocardial infarction in men $(\mathrm{P}=0.26)$ or women $(\mathrm{P}=$ 0.27 ) after multivariable adjustments.

\section{Discussion}

In this 12-15 year prospective study of 5700 men and women from the general population where persons with known diabetes or cardiovascular disease were excluded, a $1 \mathrm{SD}(87 \mu \mathrm{mol} / \mathrm{L})$ increase in serum uric acid was 
Table 2 Multiple regression analysis with cardiovascular and renal covariants, and serum uric acid as dependent variable

\begin{tabular}{|c|c|c|c|c|c|c|c|c|c|}
\hline & \multirow[b]{2}{*}{$\beta\left(95 \% \mathrm{Cl}^{*}\right)$} & \multicolumn{2}{|c|}{ Men $n=2696$} & \multicolumn{2}{|c|}{ Women $\mathrm{n}=3004$} & \multicolumn{4}{|c|}{ Men and women $n=5700$} \\
\hline & & Std. $\beta$-coeffcent. ${ }^{\dagger}$ & P-value & $\beta\left(95 \% \mathrm{Cl}^{*}\right)$ & Std. $\beta$-coeffcent. ${ }^{\dagger}$ & P-value & $\beta\left(95 \% \mathrm{Cl}^{*}\right)$ & Std. $\beta$-coeffcent. ${ }^{\dagger}$ & P-value \\
\hline \multicolumn{10}{|l|}{ Model 1} \\
\hline Intercept & $175(143,208)$ & - & $<0.001$ & $71(52,90)$ & - & $<0.001$ & $128(108,148)$ & - & $<0.001$ \\
\hline Age & $-0.70(-0.10,-0.39)$ & -0.09 & $<0.001$ & $0.55(0.30,0.80)$ & 0.08 & $<0.001$ & $-0.39(-0.61,-0.17)$ & -0.05 & 0.001 \\
\hline BMl & $8.29(7.38,9.21)$ & 0.33 & $<0.001$ & $5.31(4.73,5.88)$ & 0.32 & $<0.001$ & $6.79(6.21,7.37)$ & 0.30 & $<0.001$ \\
\hline SBP & $0.06(-0.10,0.21)$ & 0.01 & 0.49 & $0.24(0.13,0.35)$ & 0.08 & $<0.001$ & $0.24(0.13,0.35)$ & 0.06 & $<0.001$ \\
\hline Adjusted $R^{2}$ & 0.12 & & & 0.15 & & & 0.10 & & \\
\hline \multicolumn{10}{|l|}{ Model 2} \\
\hline HDL-cholesterol & $-44.42(-52.09,-36.76)$ & -0.22 & $<0.001$ & $-27.68(-33.12,-22.23)$ & -0.17 & $<0.001$ & $-61.58(-66.42,-56.74)$ & -0.32 & $<0.001$ \\
\hline Cholesterol & $10.12(7.70,12.54)$ & 0.15 & $<0.001$ & $6.38(4.50,8.26)$ & 0.12 & $<0.001$ & $6.33(4.67,7.99)$ & 0.10 & $<0.001$ \\
\hline Adjusted $R^{2}$ & & 0.17 & & 0.18 & & & 0.19 & & \\
\hline \multicolumn{10}{|l|}{ Model 3} \\
\hline \multicolumn{10}{|l|}{ Antihypertensive } \\
\hline Drugs & $26.10(16.76,35.44)$ & 0.10 & $<0.001$ & $14.19(6.55,21.83)$ & 0.06 & 0.001 & $20.37(13.66,27.08)$ & 0.07 & $<0.001$ \\
\hline Diuretics & $66.90(33.13,99.98)$ & 0.07 & $<0.001$ & $69.14(51.01,87.28)$ & 0.13 & $<0.001$ & $54.52(35.75,73.29)$ & 0.07 & $<0.001$ \\
\hline Adjusted $R^{2}$ & 0.18 & & & 0.20 & & & 0.20 & & \\
\hline \multicolumn{10}{|l|}{ Model 4} \\
\hline Current smoker & $-7.73(-13.81,-1.63)$ & -0.04 & 0.01 & $2.07(-3.02,7.16)$ & 0.01 & 0.4 & $-0.80(-5.23,3.62)$ & -0.004 & 0.7 \\
\hline Physical activity & $-7.29(-13.56,-1.02)$ & -0.04 & 0.02 & $1.17(-5.27,7.61)$ & 0.01 & 0.7 & $11.28(6.35,16.20)$ & 0.05 & $<0.001$ \\
\hline Adjusted $R^{2}$ & 0.19 & & & 0.20 & & & 0.20 & & \\
\hline \multicolumn{10}{|l|}{ Model 5} \\
\hline GFR ckd-epi & $-1.76(-2.05,-1.48)$ & -0.28 & $<0.001$ & $-1.73(-1.94,-1.51)$ & -0.32 & $<0.001$ & $-1.74(-1.91,-1.56)$ & -0.27 & $<0.001$ \\
\hline $\log A C R$ & $4.09(-2.58,10.76)$ & 0.02 & 0.23 & $15.41(9.28,21.55)$ & 0.08 & $<0.001$ & $8.09(3.58,12.61)$ & 0.04 & $<0.001$ \\
\hline Gender & -- & - & - & -- & - & - & $76.87(73.08,80.66)$ & 0.44 & $<0.001$ \\
\hline Adjusted R2 & 0.23 & & & 0.27 & & & 0.40 & & \\
\hline
\end{tabular}

${ }^{*}$ Confidence interval. ${ }^{\uparrow}$ Standarized $\beta$-coeffcient. Gender: 1 = male, 0 = female, GFR: Glomerular filtration rate according to the CKD EPI formula [17].

ACR: urinary albumin/creatinine ratio (mean of 3 urine samples) logACR: logarithmic transformation of ACR. Model 1: Age, body mass index.

(BMI), systolic blood pressure (SBP). Model 2: Model $1+\mathrm{HDL}$-cholesterol and total cholesterol. Model 3: Model $2+$ use of diuretics and other anti-hypertensive medication. Model 4: Model 3+ current smoking and

physical activity (self-reported hard physical activity $\geq 1 \mathrm{hr}$ per week; yes $=1 / \mathrm{no}=0$ ), current smoking (yes $=1 / \mathrm{no}=0$ ). Model 5 : Model $4+$ renal factors added (GFR the CKD-EPI and logACR). 

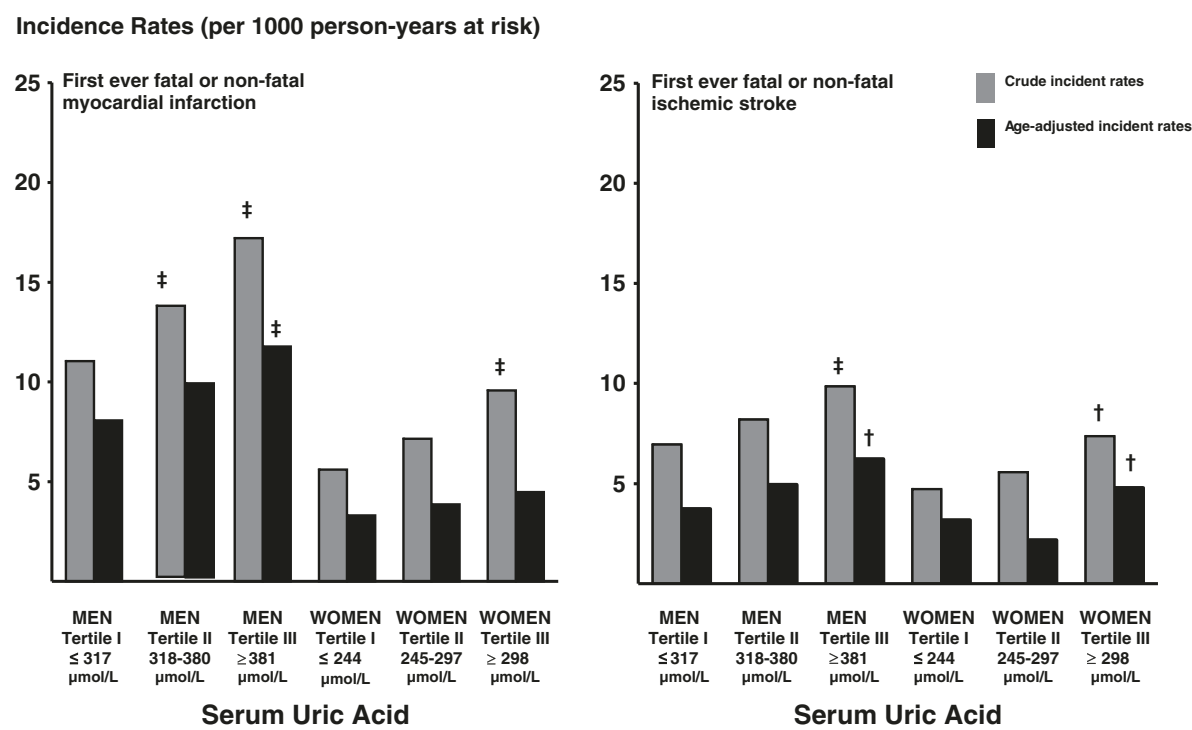

Figure 3 Crude and age-adjusted incidence rates by serum uric acid tertiles. $+: P<0.05$. $\neq: P<0.001$ (differences between tertiles were tested for using a normal test with continuity correction, tertile 1 was reference).

significantly associated with $31 \%$ increased risk for ischemic stroke in men, and all-cause mortality risk was increased in both genders, with $11 \%$ in men, and $16 \%$ in women, after multivariable adjustments. Gender-adjusted, multivariable analyses of pooled data from both men and women showed, for each 1 SD increase in serum uric acid, a $22 \%$ increased risk for ischemic stroke, and $13 \%$ increased risk for all-cause mortality.

The association between serum uric acid and ischemic stroke is in accordance with previous studies [5,19,20]. It has been suggested that serum uric acid may have harmful effects on platelet function [21] and cause endothelial dysfunction [22]. Vannorsdall et al. [23] reported that even a mild elevation of serum uric acid was associated with cerebral ischemia among community-dwelling adults. It was suggested that impaired vascular tone and endothelial dysfunction could contribute to ischemic changes, because they permit cerebrospinal fluid to cross the blood-brain barrier and cause areas of edema [23].

Quite opposite to this, it has been claimed that treatment with uric acid in combination with thrombolysis would be of benefit to patients suffering from acute stroke [24]. Uric acid is one of the most important endogenous antioxidants in the human brain, and high circulating uric acid could play a role against the deleterious effect of free radicals produced upstream in the synthesis of uric acid [24]. Accordingly, a J-curve relationship has been observed between serum uric acid and occurrence of ischemic stroke [19]. Our study did, however, not reveal any non-linear associations between serum uric acid and any of the endpoints. In women, serum uric acid lost significance as predictor for ischemic stroke when blood pressure and
BMI were included as covariates. However, no gender interaction was observed. Differences in risk estimates for stroke between genders, may relate to gender-specific differences in vascular biology such as adaption to pro-inflammatory stress. Vlachopoulos et al. [25] reported that in newly diagnosed hypertensive persons, uric acid was associated with increased aortic stiffness in both genders, however a negative association with arterial wave reflection was observed only in women. Such differences like this in vascular function could influence the tendency of developing stroke. The Framingham study [11] also reported lack of independent association of uric acid with stroke, but this is in contrast to the gender specific analyses of the AMORIS-study [5]. However, BMI and use of antihypertensive medication was not accounted for in the AMORIS study [5].

We observed a significant association of serum uric acid with all-cause mortality, with a modest increase in mortality risk in both genders. In the Framingham study [11], no association was observed with all-cause mortality among the genders after adjustments for age, blood pressure, smoking, BMI, total cholesterol, intake of alcohol and medication. On the other hand, the NHANES study [3] reported a $13 \%$ increased mortality risk in women in fully adjusted analyses, but only non-significant associations in men. The fact that serum uric acid levels in women tend to increase during the fifth to the seventh decade due to postmenopausal reduction in uric acid excretion [2,26], whereas a flat (Figure 2) or slightly declining curve with ageing is seen in men [11], may influence the association with endpoints among the genders.

No independent association between increment in uric acid and MI was observed in the present study. However, 
Table 3 Associations of serum uric acid with adverse cardiovascular events and all-cause mortality

\begin{tabular}{|c|c|c|c|c|c|c|}
\hline & & Hazard $r$ & $(95 \% \mathrm{Cl})$ per $1 \mathrm{SD} \mathrm{i}$ & ease in se & uric acid $(87 \mu \mathrm{mol} / \mathrm{L})$ & \\
\hline & Men $(n=2696)$ & P-value & Women $(n=3004)$ & P-value & Men and women $(n=5700)$ & P-value \\
\hline All-cause mortali & & & & & & \\
\hline Unadjusted & $1.01(0.94,1.09)$ & 0.6 & $1.24(1.14,1.35)$ & $<0.001$ & $1.10(1.04,1.17)$ & $<0.001$ \\
\hline Age-adjusted & $1.11(1.03,1.19)$ & 0.005 & $1.12(1.03,1.22)$ & 0.008 & $1.11(1,05,1.18)$ & $<0.001$ \\
\hline Multivariable adjustr & & & & & & \\
\hline Model 1 & $1.13(1.04,1.22)$ & 0.003 & $1.22(1.12,1.33)$ & $<0.001$ & $1.19(1.14,1.25)$ & $<0.001$ \\
\hline Model 2 & $1.13(1.05,1.23)$ & 0.003 & $1.20(1.10,1.31)$ & 0.001 & $1.17(1.01,1.24)$ & $<0.001$ \\
\hline Model 3 & $1.13(1.04,1.22)$ & 0.005 & $1.20(1.09,1.32)$ & $<0.001$ & $1.16(1,09,1.23)$ & $<0.001$ \\
\hline Model 4 & $1.12(1.04,1.22)$ & 0.005 & $1.20(1.09,1.31)$ & $<0.001$ & $1.16(1.09,1.23)$ & $<0.001$ \\
\hline Model 5 & $1.11(1.02,1.20)$ & 0.02 & $1.16(1.05,1.29)$ & 0.004 & $1.13(1.06,1.21)$ & $<0.001$ \\
\hline Myocardial infarct & & & & & & \\
\hline Unadjusted & $1.15(1.05,1.26)$ & 0.003 & $1.38(1.20,1.59)$ & $<0.001$ & $1.21(1.12,1.31)$ & $<0.001$ \\
\hline Age-adjusted & $1.22(1.11,1.34)$ & $<0.001$ & $1.21(1.06,1.40)$ & 0.006 & $1.23(1.14,1.33)$ & $<0.001$ \\
\hline Multivariable adjustr & & & & & & \\
\hline Model 1 & $1.16(1.05,1.28)$ & 0.004 & $1.16(1.01,1.35)$ & 0.049 & $1.16(1.08,1.27)$ & $<0.001$ \\
\hline Model 2 & $1.07(0.95,1.19)$ & 0.25 & $1.09(0.93,1.27)$ & 0.26 & $1.09(0.99,1.18)$ & 0.09 \\
\hline Model 3 & $1.05(0.94,1.17)$ & 0.3 & $1.10(0.94,1.29)$ & 0.22 & $1.09(0.10,1.18)$ & 0.06 \\
\hline Model 4 & $1.05(0.95,1.17)$ & 0.3 & $1.09(0.93,1.27)$ & 0.3 & $1.08(0.99,1.18)$ & 0.09 \\
\hline Model 5 & $1.05(0.94,1.17)$ & 0.4 & $1.06(0.90,1.25)$ & 0.5 & $1.06(0.97,1.16)$ & 0.19 \\
\hline Ischemic stroke & & & & & & \\
\hline Unadjusted & $1.13(1.01,1.28)$ & 0.049 & $1.37(1.17,1.61)$ & $<0.001$ & $1.21(1.10,1.33)$ & $<0.001$ \\
\hline Age-adjusted & $1.23(1.08,1.40)$ & 0.001 & $1.20(1.03,1.40)$ & 0.02 & $1.22(1.11,1.35)$ & $<0.001$ \\
\hline Multivariable adjustr & & & & & & \\
\hline Model 1 & $1.25(1.10,1.42)$ & 0.001 & $1.13(0.95,1.33)$ & 0.17 & $1.19(1.07,1.31)$ & 0.001 \\
\hline Model 2 & $1.29(1.13,1.47)$ & $<0.001$ & $1.13(0.95,1.34)$ & 0.17 & $1.22(1.09,1.35)$ & $<0.001$ \\
\hline Model 3 & $1.28(1.11,1.46)$ & $<0.001$ & $1.13(0.95,1.35)$ & 0.18 & $1.21(1.09,1.35)$ & $<0.001$ \\
\hline Model 4 & $1.28(1.12,1.47)$ & $<0.001$ & $1.12(0.94,1.34)$ & 0.20 & $1.22(1.09,1.35)$ & $<0.001$ \\
\hline Model 5 & $1.31(1.14,1.50)$ & $<0.001$ & $1.13(0.94,1.36)$ & 0.21 & $1.24(1.11,1.38)$ & $<0.001$ \\
\hline
\end{tabular}

The Tromsø Study.

Model 1: Age, body mass index (BMI), systolic blood pressure (SBP) and diastolic blood pressure (DBP).

Model 2: Model $1+$ HDL-cholesterol and total cholesterol.

Model 3: Model $2+$ use of diuretics and other antihypertensive medication.

Model 4: Model $3+$ current smoking and physical activity (physical activity $\geq 1 \mathrm{hr}$ per week; yes $=1 /$ no $=0$ ), current smoking $($ yes $=1 /$ no $=0$ ) .

Model 5: Model $4+$ renal factors added (GFR the CKD-EPI and log ACR: GFR: CKD-EPI formula [17]. Log ACR: log albumin/creatinine ratio, mean of 3 urine samples). In analyses of men and women together, adjustment for gender is included in all models.

Number of events during follow up: 659 fatal- or non-fatal myocardial infarctions, 430 fatal- or non-fatal ischemic strokes, and 1433 deaths from all causes.

significance did not depend on renal function or ACR as expected, but on lipids. Total- and HDL-cholesterol abolished the effect of uric acid on future MI. This is in consistence with a recent study [27] on the predictive value of uric acid on cardiovascular mortality among persons with type 2 diabetes in the general population. The inclusion of HDL-cholesterol, LDL-cholesterol, triglycerides, $\mathrm{BMI}, \mathrm{HbA1c}$ and blood pressure as covariates abolished the significance of a $40 \%$ risk increment found in subjects with uric acid levels $>375 \mu \mathrm{mol} / \mathrm{L}$ in sex and age-adjusted analyses [27]. Subgroups with known diabetes or cardiovascular disease were excluded in the present study, as we aimed to examine the role of uric acid in a low-risk population. Subanalyses where persons with diabetes or preexisting cardiovascular disease were included, did not change our results. Neither did stratification according to uric acid values above or less than the upper reference range. This is in contrast to the NHANES study [3], where an increased risk of ischemic heart disease mortality was observed. Hazard ratios for each $59 \mu \mathrm{mol} / \mathrm{l}$ increase in uric acid level were reported to be 1.17 (95\% CI 1.06-1.28) in men and 1.30 (95\% CI 1.17-1.45) in women [3]. However, in that study, BMI 
was higher than in the present study, and covariates such as HDL-cholesterol and drug intake were not accounted for.

The Framingham Study [11] is one of the largest studies on the association of uric acid with CVD in the general population. Our study differs from the Framingham Study [11] in many ways. Mean age was 47 years in the Framingham study compared with 60 years in the present study, and thus mortality rate was lower in the Framingham study (12.4 per 1000 person years compared to 18.9 per 1000 person years). In general, studies that have failed to discern associations between uric acid and cardiovascular disease have had shorter observation time, included younger persons, and had low number of events per-personyears. As such they may have lacked the power to identify the contribution of hyperuricemia to cardiovascular outcomes [28]. The observation time in our study was longer than in most previous studies, and this may explain why we were able to detect associations in a study population where high-risk subjects had been excluded (e.g., subjects with diabetes and known CVD). It has been claimed that uric acid is a more important risk factor among Afro Americans than among Caucasians $[3,11]$. Our study shows that uric acid is a risk factor in the Caucasian population as well.

Several mechanisms could cause the uric acid metabolic pathway to be a CV risk factor. Uric acid may stimulate vascular smooth cell proliferation, and reduce vascular nitric oxide production. For a review, see [29]. The action of xanthine oxidase leads to generation of superoxide anions [30]. This could mean that xantine oxidase activity is the key risk factor, with uric acid just an epiphenomenon. Uric acid per se has been described as a scavenger with antioxidant effects [29-32]. It is noteworthy that some preliminary intervention studies have shown that the xanthine oxidase inhibitor Allopurinol lowered blood pressure in hypertensive adolescents [33], and had anti-ischemic effects in patients with angina pectoris [34]. Allopurinol also reduced cardiovascular and hospitalization risk in a small study of patients with renal failure [35]. A recent study found that hyperuricemia was significantly associated with poor outcomes in heart failure patients without chronic kidney disease, but not in hyperuricemic persons with renal failure [36]. The latter could suggest that hyperuricemia may predict poor outcomes primarily as a marker of xanthine oxidase activity, and not due to impaired renal excretion of uric acid. Future intervention studies will hopefully explore this important issue further.

A major shortcoming of our study is that serum uric acid was done as a single measurement. Furthermore, assessment was done in a population of Caucasians only, so our results may not pertain to other ethnical groups. The study is strengthened by the solid attendance rate, a long follow-up time, the thorough validation of endpoints, and the ability to correct for confounding risk factors such as renal function, ACR, traditional cardiovascular risk factors and the use of antihypertensive medication and diuretics.

\section{Conclusion}

After multivariable adjustment, serum uric acid was significantly associated with increased risk of future ischemic stroke in men and with all-cause mortality in both genders. Associations of uric acid with myocardial infarction lost significance after adjustments for lipids. We conclude that serum uric acid is an independent marker of ischemic stroke in men, and all-cause mortality in both genders in a Caucasian, general population. Gender-specific analyses should be given priority in future studies.

\section{Competing interests}

The authors have no conflict of interest to disclose related to the present study.

\section{Authors' contributions}

Study design: HMS, IT, TJ. Data collection: MLL. Data analyses: HMS, IT, TJ, BOE. Writing the first draft: HMS, IT, TJ. Data interpretation, discussion and preparation of the final manuscript: HMS, IT, JVN, BOE, MLL, MDS, SNZ, SW, SC, TJ. All authors read and approved the final manuscript.

\section{Acknowledgements}

This work was supported by grants from the local Health Authorities (Helse Nord).

\section{Author details}

'Section of Haematology, University Hospital of North Norway, Tromsø, Norway. ${ }^{2}$ Department of Clinical Medicine, UiT The Arctic University of Norway, Tromsø, Norway. ${ }^{3}$ Section of Nephrology, University Hospital of North Norway, N-9038, Tromsø, Norway. ${ }^{4}$ Department of Community Medicine, UiT The Arctic University of Norway, Tromsø, Norway. ${ }^{5}$ Renal Division, The George Institute for International Health, University of Sydney, Sydney, Australia. ${ }^{6}$ Renal Medicine, Royal Prince Alfred Hospital,

Camperdown, Sydney, Australia. ${ }^{7}$ Department of Nephrology, Oslo University Hospital Rikshospitalet, Oslo, Norway.

Received: 16 May 2013 Accepted: 5 December 2013

Published: 11 December 2013

\section{References}

1. Feig DI, Kang DH, Johnson RJ: Uric acid and cardiovascular risk. N Engl J Med 2008, 359:1811-1821.

2. Wingrove CS, Walton C, Stevenson JC: The effect of menopause on serum uric acid levels in non-obese healthy women. Metabolism 1998, 47:435-438.

3. Fang J, Alderman M: Serum uric acid and cardiovascular mortality. JAMA 2000, 283:2404-2410

4. Madero M, Sarnak MJ, Wang X, Greene T, Beck GJ, Kusec JW, Collins AJ, Levey AS, Menin V: Uric acid and long-term outcomes in CKD. Am J Kidney Dis 2009, 53:796-803.

5. Holme I, Aastveit AH, Hammar N, Jungner I, Walldius G: Uric acid and risk of myocardial infarction, stroke and congestive heart failure in 417734 men and women in the Apolipoprotein Mortality RISK study (AMORIS). J Intern Med 2009, 266:558-570.

6. Strasak AM, Kelleher CC, Brant LJ, Rapp K, Ruttmann E, Concin H, Diem G, Pfeiffer KP, Ulmer $\mathrm{H}$ : Serum uric acid is an independent predictor for all major forms of cardiovascular death in 28,613 elderly women: a prospective 21-year follow-up study. Int J Cardiol 2008, 125:232-239.

7. Wu YQ, Li J, Xu YX, Wang YL, Luo YY, Hu DY, Liu WJ, Yang M, Pi L, Wang MS, Wang JY, Zhao SM, LI MJ: Predictive value of serum uric acid on cardiovascular disease and all-cause mortality in urban Chinese patients. Chin Med J (Engl) 2010, 123:1387-1391.

8. Niskanen LK, Laaksonen DE, Nyyssonen K, Alfthan G, Lakka HM, Lakka TA Salonen JT: Uric acid level as a risk factor for cardiovascular and all-cause mortality in middle-aged men: a prospective cohort study. Arch Intern Med 2004, 164:1546-1551. 
9. Liese AD, Hense HW, Lowel H, Doring A, Tietze M, Keil U: Association of serum uric acid with all-cause and cardiovascular disease mortality and incident myocardial infarction in the MONICA Augsburg cohort. WHO Monit Trends Determinants Cardiovasc Dis. Epidemiol 1999, 10:391-397.

10. Bengtsson C, Lapidus L, Stendahl C, Waldenstrom J: Hyperuricaemia and risk of cardiovascular disease and overall death. A 12-year follow-up of participants in the population study of women in Gothenburg, Sweden. Acta Med Scand 1988, 224:549-555.

11. Culleton BF, Larson MG, Kannel WB, Levy D: Serum uric acid and risk for cardiovascular disease and death: the Framingham Heart Study. Ann Intern Med 1999, 131:7-13.

12. Sakata K, Hashimoto T, Ueshima H, Okayama A: Absence of an association between serum uric acid and mortality from cardiovascular disease: NIPPON DATA 80, 1980-1994. National integrated projects for prospective observation of non-communicable diseases and its trend in the aged. Eur J Epidemiol 2001, 17:461-468.

13. Jee SH, Lee SY, Kim MT: Serum uric acid and risk of death from cancer, cardiovascular disease or all causes in men. Eur J Cardiovasc Prev Rehabil 2004, 11:185-191.

14. Moriarity JT, Folsom AR, Iribarren C, Nieto FJ, Rosamond WD: Serum uric acid and risk of coronary heart disease: Atherosclerosis Risk in Communities (ARIC) Study. Ann Epidemiol 2000, 10:136-143.

15. Wannamethee SG, Shaper AG, Whincup PH: Serum urate and the risk of major coronary heart disease events. Heart 1997, 78:147-153.

16. Jacobsen BK, Eggen AE, Mathiesen EB, Wilsgaard T, Njølstad I: Cohort profile: The Tromsø Study. Int J Epidemiol 2012, 41:961-967.

17. Levey AS, Stevens LA, Schmid CH, Zhang YL, Castro AF, Feldman HI, Kusek JW, Egges P, Van Lente F, Greene T, Coresh J: A new equation to estimate glomerular filtration rate. Ann Intern Med 2009, 150:604-612.

18. WHO MONICA Project Principal Investigators: The World Health Organization MONICA Project (monitoring trends and determinants in cardiovascular disease): a major international collaboration. J Clin Epidemiol 1988, 41:105-114

19. Lehto S, Niskanen L, Ronnemaa T, Laakso M: Serum uric acid is a strong predictor of stroke in patients with non-insulin-dependent diabetes mellitus. Stroke 1998, 29:635-639.

20. Kim SY, Guevara JP, Kim KM, Choi HK, Heitjan DF, Albert DA: Hyperuricemia and risk of stroke: a systematic review and meta-analysis. Arthritis Rheum 2009, 61:885-892.

21. Mustard JF, Murphy EA, Ogryzlo MA, Smythe HA: Blood coagulation and platelet economy in subjects with primary gout. Can Med Assoc J 1963, 89:1207-1211.

22. Kang DH, Park SK, Lee IK, Johnson RJ: Uric acid-induced C-reactive protein expression: implication on cell proliferation and nitric oxide production of human vascular cells. J Am Soc Nephrol 2005, 16:3553-3562.

23. Vannorsdall TD, Jinnah HA, Gordon B, Kraut M, Schretlen DJ: Cerebral ischemia mediates the effect of serum uric acid on cognitive function. Stroke 2008, 39:3418-3420.

24. Amaro S, Urra X, Gomez-Choco M, Obach V, Cervera A, Vargas M, Torres F, Rios J, Planas AM, Chamorro A: Uric acid levels are relevant in patients with stroke treated with thrombolysis. Stroke 2011, 42:S28-S32.

25. Vlachopoulos C, Xaplanteris P, Vyssoulis G, Bratsas A, Baou K, Tzamou V, Aznaouridis K, Dima I, Lazaros G, Stefanadis C: Association of serum uric acid level with aortic stiffness and arterial wave reflections in newly diagnosed, never-treated hypertension. Am J Hypertens 2011, 24:33-39.

26. Levine W, Dyer AR, Shekelle RB, Schoenberger JA, Stamler J: Serum uric acid and 11.5-year mortality of middle-aged women: findings of the Chicago Heart Association Detection Project in Industry. J Clin Epidemiol 1989, 42:257-267.

27. Panero F, Gruden G, Perotto M, Fornengo P, Barutta F, Runzo C, Ghezzo G, Cavallo-Perin P, Bruno G: Uric acid is not an independent predictor of cardiovascular mortality in a population-based study. Atherosclerosis 2012, 221:183-188.

28. Krishnan E, Sokolove J: Uric acid in heart disease: a new C-reactive protein? Curr Opin Rheumatol 2011, 23:174-177.

29. Dawson J, Quinn T, Walters M: Uric acid reduction: a new paradigm in the management of cardiovascular risk? Curr Med Chem 2007, 14:1879-1886.

30. Berry C, Hamilton CA, Brosnan MJ, Magill FG, Berg GA, McMurray JJ, Dominiczak AF: Investigation into the sources of superoxide in human blood vessels: Angiotensin II increases superoxide production in human internal mammary arteries. Circulation 2000, 101:2206-2212.
31. Higgins P, Dawson J, Walters M: The potential for xanthine oxidase inhibition in the prevention and treatment of cardiovascular and cerebrovascular disease. Cardiovasc Psychiatry Neurol 2009. http://www. hindawi.com/journals/cpn/2009/282059.

32. Nakagawa T, Kang DH, Feig D, Sanchez-Lozada LG, Srinivas TR, Sautin Y, Ejaz AA, Segal M, Johnson RJ: Unearthing uric acid: an ancient factor with recently found significance in renal and cardiovascular disease. Kidney Int 2006, 69:1722-1725.

33. Feig DI, Soletsky B, Johnson RJ: Effect of allopurinol on blood pressure of adolescents with newly diagnosed essential hypertension: a randomized trial. JAMA 2008, 300:924-932.

34. Noman A, Ang DS, Ogston S, Lang CC, Struthers AD: Effect of high-dose allopurinol on exercise in patients with chronic stable angina: a randomised, placebo controlled crossover trial. Lancet 2010, 375:2161-2167.

35. Goicoechea M, de Vinuesa SG, Verdalles U, Ruiz-Caro C, Amphuero J, Rinchon A, Arroyo D, Luro J: Effect of allopurinol in chronic kidney disease progression and cardiovascular risk. Clin J Am Soc Nephrol 2010, 5:1388-1393.

36. Filippatos GS, Ahmed MI, Gladden JD, Mujib M, Aban IB, Love TE, Sanders PW, Pitt B, Anker SD, Ahmed A: Hyperuricaemia, chronic kidney disease, and outcomes in heart failure: potential mechanistic insights from epidemiological data. Eur Heart J 2011, 32:712-720.

doi:10.1186/1471-2261-13-115

Cite this article as: Storhaug et al.: Uric acid is a risk factor for ischemic stroke and all-cause mortality in the general population: a gender specific analysis from The Tromsø Study. BMC Cardiovascular Disorders 2013 13:115.

\section{Submit your next manuscript to BioMed Central and take full advantage of:}

- Convenient online submission

- Thorough peer review

- No space constraints or color figure charges

- Immediate publication on acceptance

- Inclusion in PubMed, CAS, Scopus and Google Scholar

- Research which is freely available for redistribution 